\title{
PELAKSANAAN DOKUMENTASI ASUHAN DALAM MENINGKATKAN PELAYANAN KEPERAWATAN DI LINGKUNGAN RUMAH SAKIT
}

\author{
Kristina N Tampubolon \\ kristinatampubolon381@gmail.com
}

\begin{abstract}
ABSTRAK
Dokumentasi keperawatan sangatlah penting, akan tetapi pada kenyataannya masih banyak perawat yang kurang mengetahui dokumentasi keperawatan yang baik dan benar, salah satunya di Rumah Sakit. Tujuan dari artikel ini yaitu untuk menganalisa adanya hubungan antara pengetahuan perawat dalam dokumentasi dengan pelaksanaannya di Rawat Inap Rumah Sakit. Metode dalam penelitian ini menggunakan kuantitatif korelasi, jenis penelitian observasional dengan pendekatan crosscectional dan kuantitatif. Komponen dokumentasi asuhan keperawatan meliputi komponen isi dokumentasi dan komponen dalam konsep penyusunan dokumentasi. Komponen isi dokumentasi meliputi: pengkajian, diagnosis keperawatan, rencana keperawatan, pelaksanaan tindakan keperawatan, evaluasi, pengesahan (tanda tangan/paraf dan nama terang perawat), dan catatan keperawatan diisi secara lengkap dan jelas, resume keperawatan (Catatan pasien pulang atau meninggal dunia).Dokumentasi keperawatan mempunyai makna penting dalam aspek hukum, kualitas pelayanan, komunikasi, pendidikan, penelitian, dan akreditasi. Berkaitan dengan perlindungan hukum, dokumentasi asuhan keperawatan dapat memberi bukti yang berharga tentang kondisi pasien dan pengobatannya dan dapat bersifat kritis dalam menentukan standar perawatan apakah telah dipenuhi atau tidak. Untuk menjaga mutu dan kelengkapan dokumentasi keperawatan maka perlu adanya supervisi atau audit dokumentasi asuhan keperawatan secara kontinyu, terjadwal serta tertib. Agar mengetahui secara obyektif hasil catatan asuhan keperawatan sesuai dengan target dan standar yang dibakukan di Rumah Sakit.
\end{abstract}

Kata Kunci : Pelaksanaan Dokumentasi Keperawatan,Asuhan Keperawatan,Lingkungan Rumah Sakit,Perawat. 


\section{A. LATAR BELAKANG}

Dokumentasi keperawatan adalah setiap catatan baik tertulis maupun elektronik yang menggambarkan layanan keperawatan yang diberikan kepada klien dan dapat digunakan sebagai bukti bagi tenaga yang berwenang. Dokumentasi keperawatan yang berlaku di rumah sakit saat ini umumnya dilakukan secara tertulis (paper based documentation). Metode ini mempunyai kelemahana yaitu memerlukan waktu yang cukup lama untuk mengisi form yang tersedia, membutuhkam biaya percetakan form yang cukup mahal, sering hilang atau terselip, memerlukan tempat penyimpanan yang luas dan menyulitkan pencarian kembali saat diperlukan.

Disamping itu masih banyak perawat yang tidak tahu data apa yang harus dimasukkan dan bagaimana dokumentasi keperawatan yang benar, untuk itu perlu adanya inovasi pencatatan dengan menggunakan pencatatan berbasis elektronik. Dokumentasi keperawatan berbasis elektronik ini memberikan keuntungan bagi perawat dalam hal waktu pendokumentasian yang lebih singkat, keterbacaan data dan kemudahan akses bila dibandingkan dokumentasi dalam format kertas. Pengembangan dokumentasi keperawatan berbasis elektronik tetap harus memperhatikan prinsip kerahasiaan data klien, komprehensif, akurat, tepat waktu, dan jelas mengidentifikasi pemberi perawatan sehingga perlu adanya kebijakan dan pedoman yang jelas bagi tenaga perawat dalam menjalankan sistem ini.

Pelayanan dan asuhan keperawatan terhadap pasien merupakan bentuk pelayanan profesional yang bertujuan untuk membantu pasien memulihkan dan meningkatkan kemampuan dirinya; tindakan perawat dilakukan secara komprehensif dan berkesinambungan.Pelayanan keperawatan dilaksanakan dengan suatu sistem atau pola kerja yang disebut dengan sistem penugasan. Sistem penugasan keperawatan tidak hanya menekan-kan proses tetapi juga hasil. Hasil yang diharapkan dari sistem penugasan antara lain kepuasan kerja perawat, kepuasan pasien, lama rawat pendek, pendokumentasian asuhan optimal. Pendokumentasian asuhan keperawatan yang tidak lengkap dapat menurunkan mutu pelayanan di Rumah Sakit sehingga disarankan perawat dapat terus menjaga kualitas penulisan asuhan keperawatan sesuai dengan standar yang ditetapkan. 


\section{B. METODE}

Dalam karya ilmiah ini penulis menggunakan metode kepustakaan dengan cara membaca berbagai sumber seperti : buku,ebook,jurnal,karya ilmiah,dan sumber lainnya yang dapat dipercaya dikarenakan agar setiap pembaca tidak dipusingkan dengan artikelartikel yang kurang efektif dan belum dianalisis kebenarannya.Sumber-sumber yang dibaca dan dicari penulis juga berkenaan dengan materi permasalahan yang akan dibahas oleh penulis sehingga sistematis yang dibahas selalu berhubungan dan dapat mempermudah pemahaman pembaca.

\section{HASIL}

Dokumentasi keperawatan merupakan bukti pencatatan dan pelaporan yang dimiliki perawat dalam melakukan catatan keperawatan yang berguna untuk kepentingan klien, perawat dan tim kesehatan dalam memberikan pelayanan kesehatan. Desain penelitian adalah survei analitik dengan pendekatan cross sectional. Diharapkan bidang perawatan dapat melengkapi dokumentasi keperawatan dengan format yang sama, memberi kesempatan perawat untuk melanjutkan kuliah dan mengikuti pelatihan askep serta bertukar informasi atau gagasan antar ruang rawat. Pelaksanaan dokumentasi keperawatan merupakan salah satu alat ukur untuk mengetahui, memantau, dan menilai suatu pelayanan asuhan keperawatan yang dilakukan oleh rumah sakit.

Dokumentasi keperawatan tidak hanya mencerminkan kualitas perawatan saja tetapi membuktikan pertanggunggugatan setiap tim keperawatan.Oleh karena itu, jika kegiatan keperawatan tidak didokumentasikan dengan baik, akurat, obyektif, dan lengkap serta sesuai dengan standar asuhan keperawatan maka sulit untuk membuktikan bahwa tindakan keperawatan telah dilakukan dengan benar.

Pelayanan kesehatan sangat menentukan mutu pelayanan kesehatan. Pelayanan keperawatan merupakan bagian integral dari sistem pelayanan kesehatan sehingga pelayanan keperawatan mempunyai arti penting bagi pasien khususnya untuk penyembuhan maupun rehabilitasi di rumah sakit.Berkembangnya permintaan masyarakat terhadap pelayanan keperawatan yang berkualitas maka pelayanan keperawatan menjadi pertimbangan penting dalam pengembangan rumah sakit. 
Peningkatan mutu pelayanan di rumah sakit harus melibatkan semua unsur, termasuk didalamnya adalah unsur manajer malalui fungsi manajemen yang terdiri dari lima fungsi manajemen.

Keperawatan merupakan suatu profesi yang sangat penting dalam menentukan pemberian pelayanan kesehatan. Di rumah sakit keperawatan juga memegang peranan yang sangat strategis, dimana kebanyakan tenaga kesehatan adalah para perawat yang memberikan asuhan keperawatan.

Dokumentasi merupakan tanggung jawab dan tugas perawat setelah melakukan intervensi keperawatan. Pendokumentasian yang tidak lengkap dapat menurunkan mutu pelayanan keperawatan.

\section{PEMBAHASAN}

Dokumentasi keperawatan adalah kegiatan pencatatan dan pelaporan yang dilakukan perawat terhadap pelayanan keperawatan yang telah diberikan kepada klien, berguna untuk klien, perawat dan tim kesehatan lain sebagai tangung jawab perawat dan sebagai bukti dalam persoalan hukum.

Tujuan dokumentasi asuhan keperawatan keperawatan yaitu :

1) Menghindari kesalahan, tumpang tindih, dan ketidaklengkapan informasi dalam asuhan keperawatan.

2) Terbinanya koordinasi yang baik dan dinamis antara sesama atau dengan pihak lain melalui dokumentasi keperawatan yang efektif.

3) Meningkatkan efisiensi dan efektivitas tenaga keperawatan.

4) Terjaminnya kualitas asuhan keperawatan.

5) Tersedianya perawat dari suatu keadaan yang memerlukan penanganan secara hukum.

6) Tersedianya data-data dalam penyelenggaraan penelitian karya ilmiah, pendidikan, dan penyusun/penyempurnaan standar asuhan keperawatan.

7) Melindungi klien dari tindakan malpraktek. 
Dokumentasi keperawatan merupakan dokumentasi yang legal bagi profesi keperawatan. Oleh karena itu, dokumentasi keperawatan harus memenuhi standar yang telah ditentukan.Komisi Gabungan Akreditasi Organisasi Pelayanan Kesehatan (JCAHO) merekomendasikan standar dokumentasi keperawatan yang meliputi :

1) Pengkajian awal dan pengkajian ulang.

2) Diagnosis keperawatan dan kebutuhan asuhan keperawatan klien.

3) Rencana tindakan asuhan keperawatan.

4) Tindakan asuhan keperawatan yang diberikan atas respon klien.

5) Hasil dari asuhan keperawatan dan kemampuan untuk tindak lanjut asuhan keperawatan setelah klien dipulangkan.

Catatan pasien merupakan suatu dokumen yang legal, dari status sehat sakit pasien pada saat lampau, sekarang, dalam bentuk tulisan, yang menggambarkan asuhan keperawatan yang diberikan. Umumnya catatan pasien berisi imformasi yang mengidentifikasi masalah, diagnosa keperawatan dan medik, respons pasien terhadap asuhan kerawatan yang diberikan dan respons terhadap pengobatan serta berisi beberapa rencana untuk intervensi lebih lanjutan. Keberadaan dokumentasi baik berbentuk catatan maupun laporan akan sangat membantu komunikasi antara sesama perawat maupun disiplin ilmu lain dalam rencana pengobatan.

Standar asuhan keperawatan adalah pedoman terperinci yang menunjukan perawatan yang diprediksi dan diidentifikasi dalam situasi yang spesifik. Standar asuhan keperawatan harus menunjukan asuhan yang menjadi tanggung jawab perawat dalam pemberiannya, dan bukan tingkat ideal asuhan.

Standar asuhan keperawatan mengacu kepada tahapan proses keperawatan yang meliputi pengkajian, diagnosa keperawatan, perencanaan, implementasi, dan evaluasi. Standar I : Pengkajian keperawatan

Mencatat data yang dikaji sesuai dengan pedoman pengkajian.

Data di kelompokkan (bio-psiko-sosial-spiritual)

Data dikaji sejak pasien datang sampai pulangd.Masalah dirumuskan berdasarkan kesenjangan antara status kesehatan dengan norma dan pola fungsi kehidupan. 


\section{Standar II : Diagnosa keperawatan}

Diagnosa keperawatan berdasarkan masalah yang telah dirumuskan

Diagnosa keperawatan mencerminkan PE / PES.

Merumuskan diagnosa keperawatan aktual atau potensial.

\section{Standar III : Perencanaan keperawatan}

Berdasar diagnosa keperawatan.

Disusun menurut urutan prioritas.

Rumusan tujuan mengandung komponen pasien / subyek perubahan perilaku, kondisi pasien dan kriteria waktu.

Rencana tindakan mengacu pada tujuan dengan kalimat perintah, terinci dan jelas.

Rencana tindakan menggambarkan keterlibatan pasien / keluarga.

\section{Standar IV : Tindakan keperawatan}

Tindakan dilaksanakan mengacu pada rencana keperawatan

Perawat meng observasi respon pasien terhadap tindakan keperawatan.

Revisi tindakan berdasar evaluasi.

Semua tindakan yang sudah dilakukan dicatat dengan ringkas dan jelas.

\section{Standar IV : Evaluasi}

Evaluasi mengacu pada tujuan.

Hasil evaluasi dicatat

\section{Standar VI : Catatan asuhan keperawatan}

Menulis pada format yang baku

Pencatatan dilakukan sesuai dengan tindakan yang dilakukan.

Perencanaan ditulis dengan jelas, ringkas, istilah yang baku dan benar.

Setiap melaksanakan tindakan perawat mencantumkan paraf / nama jelas, tanggal dilakukan tindakan. 
Dokumentasi keperawatan tersimpan sesuai dengan ketentuan yang berlaku didalam kegiatan hidup sehari-hari. Pelayanan keperawatan merupakan salah satu faktor penentu baik buruknya mutu dan citra rumah sakit, oleh karenanya pekerjaan perawat perlu ditingkatkan seoptimal mungkin dan meningkatkan asuhan keperawatan perlu adanya suatu penerapan sebagai pedoman kerja bagi tenaga keperawatan.Masyarakat memerlukan pelayanan keperawatan yang bermutu dan dilandasi dengan jiwa manusiawi. Klien sebagai pengguna pelayanan kesehatan sangat memperhatikan pelayanan kesehatan dan menginginkan agar institusi pelayanan kesehatan dapat memberi pelayanan yang berkualitas dan mampu menunjukkan pengaruh interaksi dengan sistem pelayanan kesehatan terhadap seluruh kehidupan dan status kesehatan klien.

Keperawatan di indonesia saat ini masih dalam suatu proses profesionalisasi, yaitu terjadinya suatu perubahan dan perkembangan karakteristik sesuai tuntutan secara global dan lokal. Untuk mewujudkannya maka perawat harus mampu memberikan asuhan keperawatan secara profesional kepada klien.

\section{E. PENUTUP}

Dokumentasi keperawatan merupakan bukti pencatatan dan pelaporan yang dimiliki perawat dalam melakukan catatan keperawatan yang berguna untuk kepentingan klien, perawat dan tim kesehatan dalam memberikan pelayanan kesehatan. Standar asuhan keperawatan adalah pedoman terperinci yang menunjukan perawatan yang diprediksi dan diidentifikasi dalam situasi yang spesifik. Standar asuhan keperawatan harus menunjukan asuhan yang menjadi tanggung jawab perawat dalam pemberiannya, dan bukan tingkat ideal asuhan.Standar asuhan keperawatan mengacu kepada tahapan proses keperawatan yang meliputi pengkajian, diagnosa keperawatan, perencanaan, implementasi, dan evaluasi. Untuk mewujudkannya maka perawat harus mampu memberikan asuhan keperawatan secara profesional kepada klien. Dokumentasi merupakan tanggung jawab dan tugas perawat setelah melakukan intervensi keperawatan. Pendokumentasian yang tidak lengkap dapat menurunkan mutu pelayanan keperawatan. 


\section{F. DAFTAR PUSTAKA}

ASMARANI, DIAN (2015) HUBUNGAN BEBAN KERJA DENGAN KELENGKAPAN DOKUMENTASI ASUHAN KEPERAWATAN DI INSTALASI RAWAT INAP RSU ST. ELISABETH. Bachelor thesis, UNIVERSITAS MUHAMMADIYAH PURWOKERTO.

Aziz, Ahmad Hasanul (2017) HUBUNGAN ANTARA PENDIDIKAN DAN PENGETAHUAN PERAWAT DENGAN KELENGKAPAN PENDOKUMENTASIAN ASKEP DI RUANG RAWAT INAP RSUD dr. R. GOETENG TAROENADIBRATA PURBALINGGA. Bachelor thesis, Universitas Muhammadiyah Purwokerto.

DEFNI, SUSRIWETI (2017) PENGARUH PENDOKUMENTASIAN MODEL CHECKLIST TERHADAP KELENGKAPAN PENDOKUMENTASIAN ASUHAN KEPERAWATAN DI RSUD AROSUKA TAHUN 2017. Masters thesis, Universitas Andalas.

Dyah Fitri Wulandari, e. (2019). PENGEMBANGAN DOKUMENTASI KEPERAWATAN BERBASIS ELEKTRONIK DI RS X KOTA DEPOK DENGAN MENGGUNAKAN TEORI PERUBAHAN LEWINS. Jurnal Keperawatan Global,4(1), 1-73.

Erna Dwi Wahyuni, e. (2019). Faktor yang Berhubungan dengan Mutu Pendokumentasian Asuhan Keperawatan. FUNDAMENTAL AND MANAGEMENT NURSING JOURNAL,2(1), 16-23.

Josua Edison Mangole, e. (2015). HUBUNGAN PERILAKU PERAWAT DENGAN PENDOKUMENTASIAN ASUHAN KEPERAWATAN DI CARDIOVASKULAR AND BRAIN CENTER RSUP PROF. DR. R. D. KANDOU MANADO. E-journal Keperawatan (e-Kp),3(2), 1-9.

Muryani, e. (2019). KUALITAS PENDOKUMENTASIAN ASUHAN KEPERAWATAN DI RUANG RAWAT INAP (Studi di RSUD Kalimantan Tengah). Nerspedia,2(1), 27-32.

Noorkasiani, e. (2015). FAKTOR-FAKTOR YANG BERHUBUNGAN DENGAN KELENGKAPAN DOKUMENTASI KEPERAWATAN. Jurnal Keperawatan Indonesia ,18(1), 1-8.

Simamora, R. (2009). Dokumentasi Proses Keperawatan.

Simamora, R. H., Purba, J. M., Bukit, E. K., \& Nurbaiti, N. (2019). Penguatan Peran Perawat Dalam Pelaksanaan Asuhan Keperawatan Melalui Pelatihan Layanan Prima. JPPM (Jurnal Pengabdian Dan Pemberdayaan Masyarakat), 3(1), 25-31. 
Sugiyati, S. (2015). HUBUNGAN PENGETAHUAN PERAWAT DALAM DOKUMENTASI KEPERAWATAN DENGAN PELAKSANAANNYA DI RAWAT INAP RSI

KENDAL. Jurnal Keperawatan,8(2), 109 - 125.

Sumilat, Niken Pradipta (2017) Standar Pendokumentasian Asuhan Keperawatan di BLUD RSUD Kota Baubau. Undergraduate (S1) thesis, Universitas Islam Negeri Alauddin Makassar. 